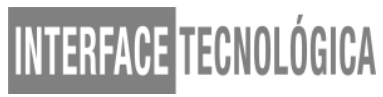

\title{
A IMPORTÂNCIA DO FATOR HUMANO NAS ORGANIZAÇÕES
}

\section{THE IMPORTANCE OF HUMAN FACTOR IN ORGANIZATIONS}

\author{
Rafael Ramos Laureano - ra.laureano0998@gmail.com \\ Faculdade de Tecnologia (Fatec) - Taquaritinga - SP - Brasil \\ Ramilio Ramalho Reis Filho - ramilio.ramalho@hotmail.com \\ Faculdade de Tecnologia (Fatec) - Taquaritinga - SP - Brasil
}

DOI: 10.31510/infa.v17i2.921

Data de publicação: 18/12/2020

\begin{abstract}
RESUMO
Ao se falar em fator humano, depare-se com um conceito que trata os indivíduos como ferramentas no mercado de trabalho. O objetivo deste artigo é demonstrar que a pessoa que se sente satisfeita no ambiente de trabalho, torna-se fator crucial para a competitividade da empresa, além de citar a importância da gestão de pessoas, pois esta trabalha com métodos, habilidades, políticas e técnicas bem definidas, para que o indivíduo possa planejar, organizar, gerir, direcionar e controlar os processos dentro de uma organização. As metodologias utilizadas neste trabalho foram de caráter bibliográfico e exploratório, a fim de comprovar a importância do tema e possibilitar que haja um estudo mais aprofundado do tema de estudo. Com o resultado das pesquisas, demonstra-se a necessidade de uma mudança de comportamento das empresas com relação aos seus colaboradores, deixando de enxerga-los como ferramentas de trabalho e de fácil reposição e passando a entendê-los como seres humanos que possuem emoções, sentimentos e objetivos pessoais, e como um fator de competitividade e um aliado na busca do sucesso da organização.
\end{abstract}

Palavras-chave: Fator humano. Gestão por Pessoas. Colaboradores. Empresa.

\begin{abstract}
When talking about the human factor, we face a concept that treats individuals as tools in the job market. The purpose of this article is to demonstrate that the person who feels satisfied in the work environment becomes a determining factor for the company's competitiveness, in addition to mentioning the importance of people management, as it works with methods, skills, policies and well-defined techniques, so that the individual can plan, organize, manage, direct and control the processes within an organization. The methodologies used in this work were bibliographic and exploratory in order to prove the importance of the theme and to allow for a more in-depth analysis of the study theme. With the results of the research, the need to change the behavior of companies towards their employees is demonstrated, ceasing to treat them as work tools and easy to replace starting to understand them as human beings who have emotions, feelings and personal goals, and as a factor of competitiveness and an ally in the search for the organization's success.
\end{abstract}


Keywords: Human fator. People management. Collaborators. Company

\section{INTRODUÇÃO}

A importância do fator humano em empresas e organizações é um tema de estudo que pode gerar muitas diversidades de opiniões, uma vez que as tecnologias e a inteligência artificial têm ganhado grande espaço nas empresas, mostrando a eficiência das máquinas, o que tem sido fator para desvalorização da mão de obra em alguns casos.

É fato que muitas organizações optam pela inteligência artificial pelo seu grande potencial benéfico em relação a custos e capacidade produtiva, além de auxiliar na tomada de decisões em uma velocidade maior do que qualquer pessoa, porém a mesma não é capaz de criar um time de trabalho, tão eficiente, quanto às equipes que têm um em que contenha indivíduos, que trocam experiências e conhecimentos, a fim de trazer melhorias para a empresa.

No presente artigo serão abordados alguns itens relevantes sobre o tema de estudo, bem como gestão de pessoas, a fim de entender sua evolução, quais as necessidades que foram atendidas e quais são os seus objetivos. Será abordada também a importância do fator humano e do indivíduo como fator de competitividade nas organizações, observando-se que com colaboradores comprometidos com os objetivos da empresa, esta terá maior sucesso no mercado competitivo.

Segundo Vergara (2012), a gestão de pessoas é um tema importante, pois é no interior de uma empresa que a maioria das pessoas passa a maior parte de suas vidas, além de que a empresa pode ter ou ser tudo, assim como um bom marketing e administração de qualidade, mas se não houver pessoas que definam visões e propósitos, ainda sim se tornarão um nada.

Ibidem, continua dizendo que as empresas são construções sociais, uma vez que as mesmas são compostas por indivíduos que necessitam de uma interação. Então é possível compreender que é de extrema importância, desvendar quais as principais necessidades que o indivíduo tem, para estender as negociações e acordos para que se atinja um objetivo. 


\subsection{Objetivos}

O objetivo deste artigo é compor um referencial teórico que enfatize o ser humano como fator importante dentro de uma empresa, destacando-o como uma determinante de competitividade, deixando evidente que uma empresa necessita de ao menos uma pessoa para que se mantenha ativa.

\subsection{Justificativa}

O tema de estudo tem sua relevância por se tratar de pessoas no mercado de trabalho e suas necessidades, ou seja, o assunto engloba não apenas um indivíduo, mas todos. Então, por meio do presente trabalho será possível identificar a importância do fator humano nas empresas e atender a satisfação dos funcionários com objetivo de criar um ambiente agradável visando maior interação entre os funcionários gerando maior produtividade.

\section{GESTÃO DE PESSOAS}

Segundo Paula e Nogueira (2016), a gestão de pessoas passou por várias modificações ao longo da história. Durante a segunda Revolução Industrial, os empresários enxergaram a necessidade de se regulamentar e aperfeiçoar os métodos trabalhistas.

A partir desse ponto, a estruturação do departamento de pessoal passou a ser realizada a fim de se regulamentar e buscar normas que garantissem o bom andamento da empresa. (IBIDEM).

Para Caldas et al. (2015), o processo de padronização da gestão de pessoas sucedeu-se com a chegada da Teoria Clássica da Administração e da Teoria da Burocracia onde adquiriram o modelo pirâmide de trabalho em que o autoritarismo e os mecanismos eram as características mais fortes deste modelo.

Costa (2010) afirma que esse processo foi lento, pois a antiga forma de administrar ainda era muito intrínseca nas empresas que resistiram ao surtir uma mudança na metodologia em uma época quando os colaboradores eram vistos como máquinas que necessitavam ser padronizadas.

Segundo Paula e Nogueira (2016, p. 4), devido às transformações do ambiente:

A teoria neoclássica surgiu, para realizar uma nova sugestão de estrutura organizacional, o modelo utilizado nessa nova teoria, deu origem a uma estrutura 
organizacional mais flexível, a fim de conseguir conectar os setores e induzi-los a uma interação mais elevada, alcançando assim uma maior produtividade.

Mello et al (2012) aborda que a partir desse momento as empresas passaram a buscar profissionais qualificados. Assim sendo, o colaborador era avaliado, recrutado e integrado, buscando aquilo que os motivava.

Então é possível concluir que um profissional qualificado e bem desenvolvido torna-se um aliado de sucesso na organização.

Figura 1 - Objetivos globais da Gestão de Pessoas

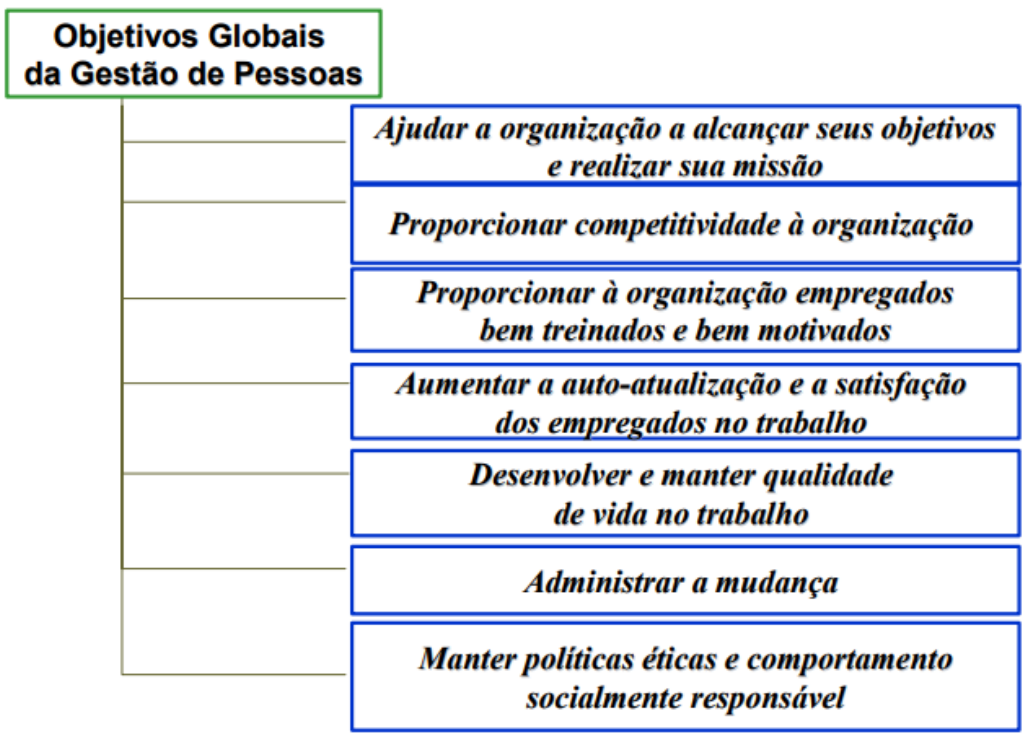

Fonte: FJG (2017).

Na Figura 1, FJG (2017) apresenta os objetivos gerais e globais da Gestão de Pessoas em relação aos quesitos de organização, competitividade, qualidade, motivação e responsabilidade social.

\subsection{A importância do fator humano nas organizações.}

Nesta seção serão observados que as empresas são ambientes sociais e que necessitam dos indivíduos para que se mantenham ativas no mercado.

Chiavenato (2011) afirma que a empresa é formada por pessoas que interagem e que contribuem para que a empresa atue em conjunto, buscando um objetivo em comum. Pode variar de pessoa para pessoa a contribuição e interação, à medida que o tempo também pode variar. Assim, as recompensas e reconhecimentos por parte das empresas também se detém de uma variação. 
A existência das empresas se dá porque indivíduos têm objetivos que somente podem ser atingidos mediante atividade organizada. Elas dependem de pessoas que planejam, dirigem e controlam suas atividades, fazendo-as operar e funcionar. Não existe organização sem pessoas, das quais dependem seu sucesso e sua continuidade. (Pontes; Kirschner, 2010, p. 3)

Ramos (2019) salienta que os colaboradores não apenas executam suas tarefas, mas também colaboram com o crescimento e a competitividade da empresa no mercado e são responsáveis também pelo funcionamento do todo, independente do seu nível hierárquico na empresa.

Segundo FJG (2017), o fator humano pode ser extremamente importante, por atuar como parceiros de uma organização, que contribuem mais que esperam retornos, são eles:

- Os acionistas e investidores: contribuem com capital de riscos e investimentos, e esperam o retorno de lucros e dividendos, e valor agregado;

- Empregados: trabalho, esforço, conhecimentos e habilidades, e querem como retorno, salário, benefícios, retribuições e satisfações;

- Fornecedores: insumos, matéria prima, serviços e tecnologias, como retorno lucros e novos negócios;

- Clientes e consumidores: compras e aquisições de bens e serviços, de retorno qualidade, preço satisfação e valor agregado. (FJG, 2017)

Com isso, é possível compreender que as pessoas devem ser vistas como parceiros importantes nas organizações, uma vez que elas contribuem com seus investimentos, habilidades, técnicas, capacidades e o principal é o capital da empresa seja eles intelectuais, de lucro, ou de investimento.

\subsection{O funcionário como fator de competitividade}

Será possível identificar um paralelo entre a qualidade de vida do trabalhador no ambiente empresarial e a vantagem competitiva que a mesma pode trazer para a empresa que adota ferramentas ou metodologias que incentivem o funcionário.

Segundo Dutra (2008), os indivíduos são fator de competitividade e cabe à empresa estimular e motivar os funcionários para que eles possam ter um bom rendimento, uma vez 


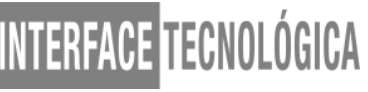

que ao mesmo tempo em que recebem da empresa, o comprometimento também deve vir na mesma medida.

Segundo Pontes e Kirschner (2010), a qualidade de vida no trabalho tem como enfoque satisfazer e atender as necessidades do funcionário na empresa, considerando que esses benefícios farão com que o funcionário produza melhor e consequentemente a empresa tenha um aumento em sua competitividade.

A qualidade de vida no trabalho é, então, fundamental para que as organizações alcancem grandes níveis de produtividade e competitividade, sem ter a ausência dos benefícios já atrelados aos colaboradores.

Cavalcanti et al (2001, p. 14), a tecnologia pode igualar as empresas, mas o fator humano as diferencia e o que pode levar uma empresa a um destaque positivo no mercado competitivo está diretamente relacionado à forma de tratamento da empresa (os superiores) com os funcionários e a satisfação do indivíduo na empresa.

\section{PROCEDIMENTOS METODOLÓGICOS}

Para o desenvolvimento deste trabalho foram utilizadas duas metodologias: a pesquisa bibliográfica e a pesquisa exploratória, com o intuito de se obter o conhecimento teórico e os dados importantes, os quais possam contribuir para destacar a importância do fator humano para as organizações.

Segundo Gil (2006, p.44), “a pesquisa bibliográfica é desenvolvida com base em material já elaborado, constituído por livros e artigos científicos”.

Já Marconi e Lakatos (2011), definem as pesquisas bibliográficas como fontes secundárias que se estendem a todo conteúdo bibliográfico, já publicado em torno de um assunto de estudo, desde publicações avulsas, até livros e artigos acadêmicos.

A segunda metodologia utilizada neste trabalho é a pesquisa exploratória. Serão realizadas entrevistas com profissionais de diversas áreas e ramo de negócios distintos, visando identificar a importância do fator humano nas empresas e quais as experiências almejam, além de buscar o grau de satisfação desses profissionais atualmente nas empresas em que estão inseridos. 
A pesquisa exploratória é caracterizada pela coleta de dados, sucede-se através de entrevistas, para proporcionar uma intimidade com o assunto de estudo, aprimorando as ideias e disponibilizando dados que comprovem um estudo envolvido. (GIL, 2006)

É fato então, que a pesquisa exploratória teve a sua fundamental importância na coleta de dados a fim de permitir que se comprove a importância da valorização dos colaboradores na empresa.

\subsection{Parâmetros e critérios}

Após as duas metodologias mencionadas terem sido selecionadas, foram estabelecidos parâmetros e critérios a fim de selecionar livros e artigos íntegros para compor a estrutura do trabalho e para a elaboração da entrevista realizada, sendo eles:

1) Livros e artigos com títulos, palavras chaves e conteúdo ligado ao fator humano nas organizações;

2) Apresentar um conceito estruturado sobre tópicos específicos ao tema;

3) Apresentar argumentos favoráveis ou não ao fator humano no mercado de trabalho;

4) Os livros e artigos devem obrigatoriamente estar publicados, fisicamente ou no formato digital através de fontes confiáveis.

O estabelecimento de parâmetros e critérios se sucedeu para que houvesse uma seleção eficiente dos livros e artigos utilizados e para que houvesse uma maior familiarização com tema, uma vez que os mesmos permitem que seja possível conhecer profissionais e estudantes interessados no assunto.

\subsection{Entrevistas e considerações}

Nesta fase foi elaborado um questionário sobre o tema de estudo que contou com 14 trabalhadores de diversas empresas de setores diferentes da economia e abrangendo a região central do estado de São Paulo, principalmente as cidades de Taquaritinga, Araraquara e Matão. Ressalta-se que o seu maior número foi composto de homens. Os entrevistados levaram um tempo médio de 2,02 minutos para responder o questionário, o qual foi criado no Forms MS-Office e enviado por meio de um link para os entrevistados. A fim de obter uma 
melhor interação com as pessoas, ficou disponível para ser respondido online durante uma semana, que se iniciou no dia 2 de setembro 2019 e finalizou no dia 9 de setembro de 2019.

Foi possível constatar por meio das entrevistas que o fator humano é de extrema importância para as organizações, bem como fator de competitividade e as melhorias que a empresa deve realizar para satisfazer as necessidades do funcionário. Os entrevistados responderam perguntas sobre atuais condições deles no trabalho em que exercem, confirmando a necessidade do uso de metodologias ou benefícios que incentivem o colaborador.

Perguntas do questionário:

1) De 1 a 10 quão importante é o fator humano para que a empresa se mantenha ativa no mercado?

2) De 1 a 10 quanto você considera importante a valorização do fator humano nas organizações?

3) Você considera que o profissional possa ser considerado como fator de competitividade para empresa?

4) Você já se sentiu desvalorizado como profissional em alguma empresa que já trabalhou ou trabalha atualmente?

5) De 1 a 10 classifique a sua satisfação atualmente na empresa em que trabalha?

6) Você considera importante que a empresa adote metodologias que tragam benefícios ao trabalhador?

\subsection{Questionário utilizado para se obter dados.}

Cada colaborador recebeu uma mensagem na qual continha o link de acesso à interface do questionário. O mesmo foi respondido estritamente por pessoas que trabalham em alguma organização, a fim de que pudesse haver uma coleta de dados mais eficiente para a pesquisa.

A Figura 2 ilustra a interface do questionário enviado aos entrevistados. Na barra de objetivos do questionário é possível visualizar uma breve descrição, a qual salienta que o autor não deseja utilizar dados pessoais do entrevistado e deixando claro que o mesmo tem como finalidade gerar dados que colaborem para a construção de uma pesquisa.

Figura 2 - Interface do questionário 


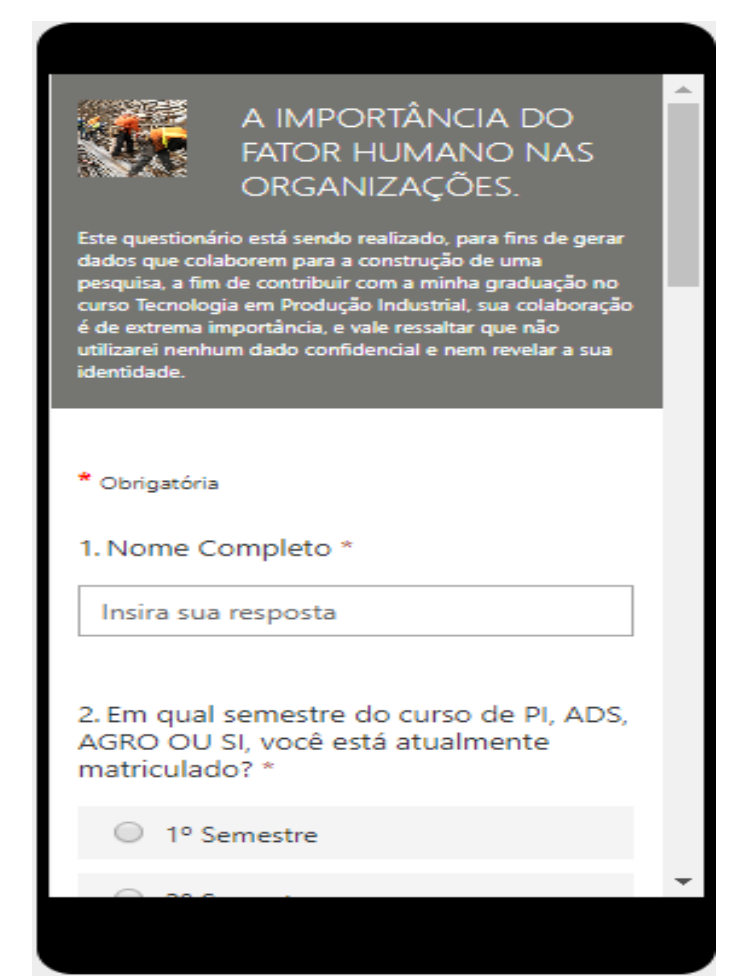

Fonte: Elaboração própria (2019).

\section{RESULTADOS E DISCUSSÃO}

A análise das respostas iniciou-se do objetivo principal do presente artigo, que é a importância do fator humano nas empresas. Os valores abaixo demonstrados estão relacionados com as respostas que os indivíduos consideraram mais coerentes com as atuais realidades deles.

- Questão 1: Ao realizar uma média, de acordo com as 14 respostas dadas, é possível identificar que as pessoas acreditam que de 1 a 10, a importância do fator humano em uma empresa é 9.

- Questão 2: Em média, os entrevistados atribuíram a nota de 9,43 \% para a importância de as organizações valorizarem os trabalhadores.

- Questão 3: A partir da resposta 3, a relação dos gráficos apresentados na Figura 3, aponta para o segundo objetivo do artigo, que é a identificação dos funcionários como fator de competitividades nas organizações. É possível observar o gráfico de pizza formado a partir das respostas dos entrevistados. 
Figura 3 - Gráfico relacionado às respostas da questão 3.

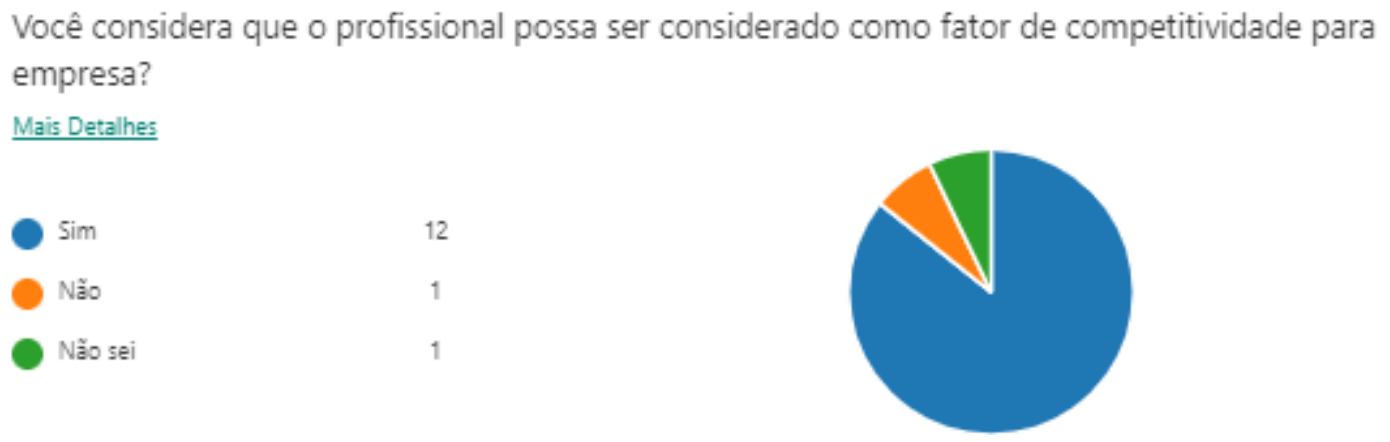

Fonte: Elaboração Própria (2019).

- Questão 4: Dos 14 entrevistados, dez alegaram que já se sentiram desvalorizados no ambiente de trabalho, três alegaram não se recordar de nenhum fato sobre o assunto e um diz nunca ter sido desvalorizado nas empresas que trabalhou.

Figura 4 - Gráfico pizza de acordo com as respostas dadas pelos entrevistados

Você já se sentiu desvalorizado como profissional, em alguma empresa que já trabalhou ou trabalha atualmente?

Mais Detalhes

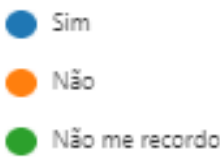

10

1

3

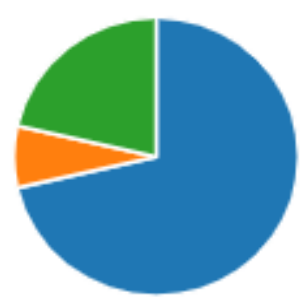

Fonte: Elaboração própria (2019).

- Questão 5: O número médio atribuído pelos entrevistados à satisfação com o emprego atual é 7,79 .

- Questão 6: É unanimidade que as empresas adotem metodologias que incentivem e tragam benefício ao trabalhador.

Ao analisar as respostas dadas ao questionário, é possível analisar que as pessoas acreditam que a mão de obra, ou seja, o fator humano é imprescindível em qualquer 
organização, assim como satisfazer as necessidades do trabalhador, pode cooperar para que o mesmo melhore seu desempenho e comprometimento com a empresa.

Ao comparar o referencial teórico com os resultados obtidos, é possível notar a real necessidade da motivação dentro das organizações, uma vez que $100 \%$ dos entrevistados acreditam que as empresas devam adotar metodologias de incentivo. Ficou também demonstrado que $90 \%$ dos entrevistados concordam que o fator humano deve ser considerado fator de competitividade nas empresas, pois são as pessoas que possibilitam o funcionamento da empresa como um todo.

\section{CONCLUSÃO}

Ao final deste trabalho, é possível compreender que as empresas, indústrias e organizações não atuam sozinhas e que as pessoas, cargos e funções são necessários nesses ambientes. Esse é, de fato, o primeiro passo para a valorização do fator humano, uma vez que equipes, empresas, corporações e governos são resultados do trabalho de pessoas.

O foco foi propor um tema que apresentasse o colaborador como ferramenta fundamental nas empresas, a fim de que as mesmas possam valorizar e desenvolver cada vez mais os mesmos, com benefícios e incentivos para motivar e influenciar os seus colaboradores a se sentirem confortáveis com o ambiente em que trabalham.

É necessário destacar que os benefícios e vantagens não somente são direcionados aos colaboradores, mas também quando as empresas têm funcionários qualificados e satisfeitos com o ambiente em que trabalham dificilmente a empresa terá quedas na produtividade, qualidade e competitividade.

Assim, as considerações finais sobre o tema estudado é que se faz necessário que as organizações enxerguem os seus funcionários como fatores fundamentais de competitividade, além de buscar trazer benefícios e melhorias no ambiente de trabalho, para que se tenha sucesso não só no mercado empresarial, mas também na procura das pessoas por uma empresa que respeite o ser humano como funcionário.

\section{REFERÊNCIAS}

CALDAS, P. T. et al. Administração de Pessoal ou Gestão de Talentos? Um estudo nas Administrações Públicas do Cariri Paraibano. XVII Semead, 2015. Disponível em: < 
http://sistema.semead.com.br/18semead/resultado/trabalhosPDF/846.pdf>. Acesso em: 5 set. 2019

CAVALCANTI, M. et al. Gestão de empresas na sociedade do conhecimento. Rio de Janeiro: Campus, 2001.

COSTA, P. C. Gestão de Pessoas: Arte ou Ciência. Rh portal- Rh pratica. Out. 2010.

CHIAVENATO, I. Teoria Geral da Administração. Elsevier: Rio de Janeiro: 2011.

DUTRA, J. S. Gestão de pessoas: modelo, processos, tendências e perspectivas. São Paulo: Atlas, 2008

FJG. Gestão de Pessoas. [S. l.]: FJG, 2017. E-book.

GIL, A. C.; Como elaborar projetos de pesquisa. 4 ed. São Paulo: Atlas, 2006.

MARCONI, M. A.; LAKATOS, E. M.; Técnicas de Pesquisas: planejamento e execução de pesquisas, amostragens e técnicas de pesquisa, elaboração, análise e interpretação de dados. 7 ed. São Paulo: Atlas, 2011.

MELO, F. A. O. et al. Influência da Gestão de Pessoas no Desempenho Empresarial através do perfil do Líder. IX Seget, 2012. Disponível em: <

https://www.aedb.br/seget/arquivos/artigos12/25416357.pdf>. Acesso em: 5 set. 2019

PAULA, V. V. de; NOGUEIRA, G. de M. A importância da área de gestão de pessoas, para o sucesso da organização. INOVARSE, [S. l.], ed. 13, 2016. Disponível em: $<$ http://www.inovarse.org/sites/default/files/T16_047.pdf. > . Acesso em: 5 set. 2019.

PONTES, Ana Valéria Vargas Pontes; KIRSCHNER, Ana Maria. O fator humano como fonte de competitividade organizacional. 2010. 21 f. Artigo (Superior e Administração) Faculdade Metodista Grambery, [S. l.], 2010. Disponível em:

$<$ http://re.granbery.edu.br/artigos/Mzcx.pdf.>. Acesso em: 4 set. 2019.

RAMOS, A. M. A importância da gestão de pessoas como fator humano nas organizações. [S. l.]: Central do Trabalho,2019. Disponível em:

$<$ http://www.centraldotrabalho.com.br/artigo/a-importancia-da-gestao-de-pessoas-comofator-humano-nas-organizacoes.html>. Acesso em: 12 de set. 2019

SCHERMANN, Daniela. Pirâmide de Maslow: o que é e porque você precisa conhecê-la?. [S. l.]: OpinionBox, 2 abr. 2018. Ilustração. Disponível em: $<$ https://blog.opinionbox.com/piramide-de-maslow/.>. Acesso em: 6 set. 2019.

VERGARA, S. C. Gestão de pessoas. 2. ed. São Paulo: Atlas, 2012. 